\title{
Mineralização do nitrogênio proveniente da aplicação do resíduo da indústria processadora de goiabas em Argissolo
}

\author{
Henrique Antunes de Souza $\left({ }^{1 *}\right)$; William Natale $\left({ }^{2}\right)$; Viviane Cristina Modesto $\left({ }^{2}\right)$; \\ Danilo Eduardo Rozane (3) \\ (') Embrapa Caprinos e Ovinos, Caixa Postal 145, 62010-970 Sobral (CE), Brasil. \\ (2) UNESP, Faculdade de Ciências Agrárias e Veterinárias, Departamento Solos e Adubos, Via de Acesso Prof. Paulo Donato \\ Castellane, s/n, 14884-900 Jaboticabal (SP), Brasil \\ (3) UNESP, Campus Experimental de Registro, Rua Nelson Brihi Badur, 430, 11900-000 Registro (SP), Brasil. \\ (*) Autor correspondente: henrique@cnpc.embrapa.br
}

Recebido: 30/out./2010; Aceito: 13/abr./2011

\section{Resumo}

Informações sobre a mineralização de subprodutos são importantes para o correto manejo desses materiais em áreas agrícolas. Assim, objetivou-se avaliar a mineralização do nitrogênio proveniente do resíduo da indústria processadora de goiabas, aplicado em Argissolo cultivado com goiabeiras. Amostras do solo mais o subproduto foram acondicionados em frascos de polietileno com capacidade de $0,25 \mathrm{dm}^{3}$. Foram pesados $100 \mathrm{~g}$ de solo mais o resíduo referente a cada tratamento (doses do subproduto: 0; 9; 18 e $36 \mathrm{t} \mathrm{ha}^{-1}$ ), sendo tal procedimento realizado em triplicata. 0 período máximo de incubação foi de 11 semanas, analisando-se as amostras nos seguintes tempos: 0; 7; 14; 28; 42; 56; 70; 84; 98 ; 112 e 126 dias. A umidade foi corrigida para 70\% da capacidade de retenção de água do solo, sendo monitorada diariamente através de pesagens dos potes. Nos tempos estabelecidos realizou-se a desmontagem de três frascos correspondentes a cada tratamento, determinando-se o nitrogênio inorgânico. Pode-se afirmar que a mineralização do N ou a liberação é lenta, ou seja, não há rápida disponibilização de nitrogênio. No período avaliado, 126 dias, a fração média de mineralização foi de $23 \%$ e, a meia vida média de 73 dias.

Palavras-chave: Psidium guajava, agroindústria, adubação orgânica, subproduto, sementes de goiaba.

\section{Nitrogen mineralization from the application of the residue of guava processing industry in Ultisol}

\begin{abstract}
Information on the mineralization of residues are important for proper management of these materials in agricultural areas. The objective was to evaluate the mineralization of nitrogen from the residue of guava processing industry, applied in a Ultisol cultivated with guava trees. Soil samples and the residue were placed in polyethylene pots with a capacity of $0.25 \mathrm{dm}^{3}$. Around $100 \mathrm{~g}$ of soil plus waste were weighed in each treatment (doses of residue: $0,9,18$ and $36 \mathrm{t} \mathrm{ha}^{-1}$ ), with such a procedure being performed in triplicate. The maximum incubation period was 11 weeks, with analyses at 0, 7, 14, 28, 42, 56, 70, 84, 98,112 and 126 days of treatment. The soil+residue humidity was adjusted to $70 \%$ of the soil water retention capacity and monitored daily by weighing the pots. The inorganic nitrogen was measured in each evaluation time. It can be stated that the $\mathrm{N}$ mineralization or release is slow and there is not rapid availability of nitrogen. Over the period of 126 days, the mean fraction of mineralization was $23 \%$ with the half-life of 73 days.
\end{abstract}

Key words: Psidium guajava, industry of food, organic fertilizer, by-product, seeds of guava. 


\section{INTRODUÇÃO}

A utilização de resíduos orgânicos, urbanos ou industriais, em áreas agrícolas pode ser justificada pela necessidade de um destino apropriado para esses materiais visando à sua reciclagem, visto que a geração desses resíduos tem aumentado rapidamente com o tempo.

Em todo o mundo as preocupaçóes e as pesquisas com adubaçẫo orgânica têm voltado ao centro das discussões. É crescente o interesse dos governos, das instituiçôes agronômicas e dos produtores rurais, por informaçóes sobre o tema. Entretanto, ainda que a reciclagem de materiais orgânicos seja cada vez mais importante, os conhecimentos sobre seu valor fertilizante para a agricultura permanecem rudimentares.

Uma alternativa interessante é procurar utilizar corretamente os resíduos na propriedade, buscando novas fontes de insumos e materiais náo convencionais, o que pode ser uma real oportunidade para a diversificaçáo da propriedade agrícola.

O mercado de frutas frescas e de matéria-prima para a industrialização é altamente promissor. Além disso, o Brasil possui bom potencial edafoclimático, com aptidão para a maioria das frutíferas de interesse comercial. Com a industrialização das frutas há a geração de resíduos, os quais, se bem manejados, podem retornar ao pomar reduzindo a utilizaçáo de adubos minerais, e, diminuindo os impactos ambientais negativos de um descarte inadequado.

Do ponto de vista da nutriçáo nitrogenada das plantas, não importa qual a fonte escolhida para a adubação (orgânica ou química), desde que usada adequadamente e seja capaz de disponibilizar $\mathrm{N}$ às plantas em formas minerais. Durante a mineralização de resíduos orgânicos no solo, um dos produtos é o amônio $\left(\mathrm{NH}_{4}^{+}\right)$, que pode ser retido pelo solo, absorvido pelas plantas ou convertido em nitrato $\left(\mathrm{NO}_{3}^{-}\right)$. O nitrato, por sua vez, pode ser absorvido pelas plantas, lixiviado para fora da zona de absorção das raízes ou ser convertido em nitrogênio gasoso, sendo perdido para a atmosfera (Boeira, 2004).

A fração de mineralização de nitrogênio dos materiais orgânicos pode ser usada como um dos critérios para a definição de doses máximas a aplicar em determinada situação de solo, de clima e cultura, quando náo houver outros critérios mais restritivos ao uso do resíduo como elevadas concentraçôes de fósforo, de metais pesados, de patógenos, ou de outras substâncias prejudiciais (BoEIRA, 2004).

A agroindústria de processamento de goiabas gera um resíduo constituído basicamente de sementes, rico em nitrogênio. Desse modo, objetivou-se avaliar a mineralização do nitrogênio desse subproduto, em condiçóes aeróbicas e sem lixiviação.

\section{MATERIAL E MÉTODOS}

Para a determinação da fração de mineralização do nitrogênio $(F M N)$ do resíduo da indústria processadora de goiabas seguiu-se os procedimentos de Coscione e Andrade (2006). As avaliaçôes foram realizadas em Jaboticabal (SP).

O solo utilizado foi coletado em pomar de goiabeiras adulto com oito anos de idade, cultivar Paluma, em Vista Alegre do Alto (SP). A amostra do Argissolo VermelhoAmarelo (EMBrapa, 1999) foi coletada na camada superficial de 0-20 cm, sendo caracterizada em termos químicos segundo Raij et al. (2001), cujos resultados sáo: 5,6; $16 ; 47 ; 2,9 ; 34 ; 22 ; 18 ; 58,5 ; 76,9$ e 77 para $\mathrm{pH}\left(\mathrm{CaCl}_{2}\right)$; M.O. $\left(\mathrm{g} \mathrm{dm}^{-3}\right)$; P $\left(\mathrm{mg} \mathrm{dm}^{-3}\right)$; K; Ca; Mg; SB; $\mathrm{H}+\mathrm{Al} ; \mathrm{T}$ (mmolc $\left.\mathrm{dm}^{-3}\right)$ e $\mathrm{V}(\%)$ respectivamente.

De acordo com os dados apresentados para a análise de solo, verifica-se que as condições de saturação por bases e fertilidade do solo estão adequadas para a cultura da goiaba, segundo Natale et al. $(1996 ; 2007)$.

As características químicas do resíduo utilizado no estudo são as seguintes: 4,6;11,6; 1.749; 18,7; 290; 2,1; 2,3; 0,$8 ; 0,9 ; 1,3 ; 10 ; 10 ; 150 ; 12 ; 28$ e 25 para $\mathrm{pH}\left(\mathrm{CaCl}_{2}\right)$; $\mathrm{N}$ total $\left(\mathrm{g} \mathrm{kg}^{-1}\right)$; N-NH4+; N-NO-3 (mg kg$\left.{ }^{-1}\right)$; C org; P;

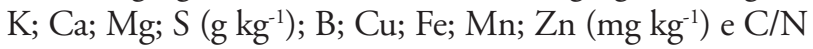
respectivamente, determinadas de acordo com ABreu et al. (2009). O resíduo é um material orgânico considerado "limpo", visto ser formado basicamente de sementes da fruta e alguma mucilagem, com teores dos elementos essenciais próximos ao das sementes frescas, conforme determinaçáo de Côrrea et al. (2005). O material foi obtido na Indústria de Polpas e Conservas Val Ltda., localizada no município de Vista Alegre do Alto (SP). Ainda na indústria, em pátio aberto, o resíduo foi exposto ao sol para secar e, em seguida, moído. Conforme a Instrução Normativa 25 (BRASIL, 2009), fez-se a caracterização física do resíduo moído, determinando-se as granulometrias: retido $0,044 \%$ na peneira ABNT 10; 25,51\% na peneira ABNT 20; 61,25\% na peneira ABNT 50 e, $13,20 \%$ passante na peneira ABNT 50. Determinou-se, também, a umidade gravimétrica do subproduto, após secagem a $65-70{ }^{\circ} \mathrm{C}$, em estufa de circulação forçada de ar. O material continha $6,45 \%$ de teor de água. Segundo a legislação vigente (BRASIL, 2009), que regulamenta as especificaçóes de compostos e biofertilizantes, o resíduo pode ser classificado como fertilizante orgânico simples, classe "A", cujas características são: a produção utiliza matéria-prima de origem vegetal ou de processamento da agroindústria, não empregando no processo metais pesados tóxicos, elementos ou compostos orgânicos sintéticos potencialmente tóxicos, resultando em produto de utilização segura na agricultura.

Foram incubadas quatro doses do subproduto com o Argissolo, equivalentes a zero; 9; 18 e $36 \mathrm{t} \mathrm{ha}^{-1}$ de resíduo adicionado ao solo, sem lixiviação. Vale ressaltar que a dose de $18 \mathrm{t} \mathrm{ha}^{-1}$ corresponde à recomendação de $\mathrm{N}$ para goiabeiras adultas, para uma produção esperada de $60 \mathrm{t} \mathrm{ha}^{-1}$ de frutos (Natale et al., 1996).

As amostras do solo mais o resíduo foram acondicionados em frascos de polietileno com capacidade de 
$0,25 \mathrm{dm}^{3}$. Foram pesados $100 \mathrm{~g}$ de solo, mais o resíduo referente a cada tratamento, sendo tal procedimento realizado em triplicata.

O período de incubação máximo foi de 11 semanas, analisando-se as amostras nos seguintes tempos: $0 ; 7 ; 14$; 28; 42; 56; 70; 84; 98; 112 e 126 dias. A umidade foi corrigida para $70 \%$ da capacidade de retenção de água do solo (CRAS), segundo Coscione e Andrade (2006), sendo monitorada diariamente através da pesagem dos potes.

Nas datas predeterminadas realizou-se a desmontagem de três frascos, correspondentes a cada tratamento, determinando-se o nitrogênio inorgânico, segundo método proposto por Cantarella e Trivelin (2001), que consiste na destilaçáo de extratos do solo em $\mathrm{KCl} 1 \mathrm{~mol}$ $\mathrm{L}^{-1}$, em microdestilador Kjeldahl e, subsequente titulação do destilado. A umidade do solo foi determinada e os resultados foram corrigidos para solo seco.

Paralelamente à avaliaçáo do nitrogênio inorgânico, realizou-se a determinaçáo do $\mathrm{pH}$, nos mesmos tempos de incubaçáo, segundo a metodologia de RAIJ et al. (2001).

Os dados foram ajustados à equaçáo de regressão exponencial de cinética de primeira ordem (Coscione e ANDRADE, 2006):

$\mathrm{Nm}=\mathrm{N}_{0}\left(1-\mathrm{e}^{-\mathrm{kt}}\right)$

em que:

$\mathrm{Nm}=\mathrm{N}$-inorgânico mineralizado $\left(\mathrm{mg} \mathrm{kg}^{-1}\right)$ no tempo $\mathrm{t}$ (dias);

$\mathrm{N}_{0}=\mathrm{N}$-potencialmente mineralizável $\left(\mathrm{mg} \mathrm{kg}^{-1}\right)$; e

$\mathrm{k}=$ constante de mineralização $\left(\mathrm{dia}^{-1}\right)$.

Foi calculado o valor de $\mathrm{T}^{1} / 2$, que é o tempo necessário para que metade do $\mathrm{N}_{0}$ seja mineralizado: $\mathrm{T}^{1 / 2} / 2=\ln 2 / \mathrm{k}$.

A fração de mineralização (FM), que é a porcentagem de $\mathrm{N}$ orgânico aplicado e mineralizado no período de incubaçáo, foi calculada de acordo com CЕTESB (1999) e Coscione e Andrade (2006):

$F M=\left(\left(\mathrm{Nm}-\mathrm{Nm}_{0}\right) /\right.$ Nadicionado $) / 100$

em que:

$\mathrm{Nm}$ : $\mathrm{N}$-mineralizado no tratamento com resíduo, em $\mathrm{mg} \mathrm{kg}^{-1}$; $\mathrm{Nm}_{0}$ : $\mathrm{N}$-mineralizado no tratamento sem resíduo, em $\mathrm{mg} \mathrm{kg}^{-1}$; e

Nadicionado: quantidade de $\mathrm{N}$ adicionado, em $\mathrm{mg} \mathrm{kg}^{-1}$.
O nitrogênio disponível foi determinado da seguinte maneira, também de acordo com Ceтеsв (1999), para a aplicação do resíduo na superfície:

$\mathrm{N}$ disponível $=(\mathrm{FM} / 100) \times(\mathrm{Nkj}-\mathrm{Na})+0,5 \times(\mathrm{Na})+$ $(\mathrm{Nn}+\mathrm{Ni})$

em que:

FM = Fração de mineralização (\%);

$\mathrm{Nkj}=$ Nitrogênio total $($ Kjedahl $)\left(\mathrm{mg} \mathrm{kg}^{-1}\right)$;

$\mathrm{Na}=$ Nitrogênio amoniacal $\left(\mathrm{mg} \mathrm{kg}^{-1}\right)$;

$\mathrm{Nn}=$ Nitrogênio nitrato $\left(\mathrm{mg} \mathrm{kg}^{-1}\right)$; e

$\mathrm{Ni}=$ Nitrogênio nitrito $\left(\mathrm{mg} \mathrm{kg}^{-1}\right)$.

Com os resultados de FM e $\mathrm{N}$ disponível foi calculada a taxa de aplicação (TA), seguindo a mesma fórmula utilizada para lodos de esgoto (Cetesb, 1999; Abreu et al., 2009):

TA $\left(\mathrm{kg} \mathrm{ha}^{-1}\right)=\mathrm{N}$ recomendado $\left(\mathrm{kg} \mathrm{ha}^{-1}\right) / \mathrm{N}$ disponível $\left(\mathrm{kg} \mathrm{kg}^{-1}\right)$

Para os cálculos do nitrogênio recomendado, considerou-se a sugestão de Natale et al. (1996), de 800 g de N por planta, para uma produtividade de $60 \mathrm{t} \mathrm{ha}^{-1}$ de frutos, em goiabeiras adultas, cultivar Paluma, no espaçamento de 7 × $5 \mathrm{~m}$ (padrão para a cultivar).

Os valores resultantes foram tabelados segundo recomendação de Coscione E Andrade (2006).

\section{RESULTADOS E DISCUSSÃO}

Os valores médios de nitrogênio inorgânico $\left(\mathrm{NH}_{4}^{+}+\mathrm{NO}_{3}^{-}\right)$, para cada dose do subproduto e tempo de incubação estão apresentados na tabela 1 .

Analisando os valores de nitrogênio líquido verificamse valores negativos, em alguns tempos, os quais podem ser devidos a uma possível imobilização do N (Tabela 2). Tal comportamento também foi constatado em outro trabalho com incubação de resíduos, ou seja, uma imobilização inicial do N (BoeIra et al., 2002).

Alguns estudos já foram realizados com o resíduo da indústria processadora de goiabas, com o objetivo de retornar este material aos pomares de goiabeiras, minimizando o uso de adubos químicos, como CorrêA et al. (2005) e Mantovani et al. (2004), indicando o potencial de uso deste subproduto como fonte de nutrientes para as plantas.

Tabela 1. Valores médios de nitrogênio inorgânico $\left(\mathrm{mg} \mathrm{kg}^{-1}\right)$ extraído do solo, em função da aplicação do resíduo da indústria processadora de goiabas

\begin{tabular}{|c|c|c|c|c|c|c|c|c|c|c|c|}
\hline \multirow{2}{*}{$\begin{array}{c}\text { Doses de resíduo } \\
\left(\mathrm{t} \mathrm{ha}^{-1}\right)\end{array}$} & \multicolumn{11}{|c|}{ Tempos de incubação (dias) } \\
\hline & 0 & 7 & 14 & 28 & 42 & 56 & 70 & 84 & 96 & 112 & 126 \\
\hline 0 & 1,08 & 24,16 & 5,37 & 6,37 & 5,04 & 1,81 & 4,12 & 1,90 & 16,56 & 3,34 & 3,34 \\
\hline 9 & 3,26 & 33,05 & 15,66 & 8,77 & 6,08 & 4,44 & 9,10 & 6,84 & 28,99 & 8,28 & 21,30 \\
\hline 18 & 5,04 & 28,32 & 12,35 & 9,57 & 11,38 & 9,78 & 25,37 & 24,57 & 24,06 & 10,30 & 31,55 \\
\hline 36 & 6,16 & 27,25 & 15,81 & 13,38 & 14,99 & 14,80 & 17,65 & 26,16 & 18,98 & 12,31 & 40,36 \\
\hline
\end{tabular}


Na tabela 3 são apresentados os dados da fração de mineralização do nitrogênio (FMN), para cada dose utilizada, após a incubação por 126 dias. De acordo com os resultados, podese observar que a FMN média das três doses foi de $23 \%$. A relação C/N (25:1) indica que o resíduo possui boas quantidades de material energético e proteico, possibilitando adequada mineralização do nitrogênio. Pode, porém, haver variação na fração de mineralização do $\mathrm{N}$, como em estudos com lodo de esgoto (BoEıra et al., 2002). Assim, a avaliação da fração de mineralização observada no presente estudo, torna-se importante para o conhecimento da liberaçáo de $\mathrm{N}$ para as culturas.

A fraçáo de mineralização de $\mathrm{N}$ representa a quantidade de nitrogênio presente em compostos orgânicos que será liberada no solo. No processo de mineralização, o $\mathrm{N}$ se torna disponível para absorção pelas plantas nas formas de nitrato, nitrito e compostos amoniacais (BoeIra et al., 2009).

A rápida mineralizaçáo inicial, seguida de diminuiçáo e tendência à estabilização após algumas semanas, é comum em estudos de mineralização de resíduos aplicados em solos (Mantovani et al., 2006).

Mantovani et al. (2006) estimaram a fração de mineralização de $12 \%$ para composto de lixo urbano incubado por 126 dias em Argissolo. Verificaram, ainda, que com a aplicação das maiores doses de composto de lixo, houve menores fraçôes de mineralizaçáo. Os autores justificaram esse resultado como decorrente de perdas de $\mathrm{N}$ por desnitrificaçáo, em funçáo do aumento das doses de adubo orgânico aplicado.
Por outro lado, a rápida mineralização inicial de grandes quantidades de $\mathrm{N}$ poderá ocorrer bem antes do que as plantas, como as anuais, tenham desenvolvido um sistema radicular capaz de absorver todo o amônio ou o nitrato que é gerado; esse $\mathrm{N}$ poderá, então, ser perdido por volatilização, ou lixiviado no perfil do solo, diminuindo o efeito benéfico para a nutriçãao das culturas, podendo incorrer impacto ambiental indesejado (BoeIra, 2004). Porém, no presente estudo, a planta que se beneficiará da aplicação do resíduo é uma frutífera perene adulta (goiabeira), ou seja, tal fato, de um rápido aporte de $\mathrm{N}$ ser perdido por lixiviaçáo, pela não formação de um extenso sistema radicular, possivelmente é minimizado, haja vista que a goiabeira tem um sistema radicular profundo e abrangente (Fracaro e Pereira, 2004).

$\mathrm{Na}$ tabela 4 são apresentados os dados referentes ao ajuste do modelo de cinética de primeira ordem, correspondendo ao nitrogênio potencialmente mineralizável em todo o período (126 dias), além da constante de velocidade de reação de mineralização e, da meia vida de mineralizaçáo. Com esses resultados, pode-se estimar o potencial de mineralização de $\mathrm{N}$ do solo tratado com o resíduo, ou seja, a quantidade máxima esperada do nutriente (em formas inorgânicas) que será liberado no solo tratado com o subproduto, na dose correspondente àquela aplicada (BoeIrA, 2004).

$\mathrm{O} N$ potencialmente mineralizável $\left(\mathrm{N}_{0}\right)$ aumentou com a aplicação das doses de resíduo, sendo a variaçáo entre 69,04 e 292,88 $\mathrm{mg} \mathrm{kg}^{-1}$ (Tabela 4). Assim, verifica-

Tabela 2. Nitrogênio líquido mineralizado $\left(\mathrm{mg} \mathrm{kg}^{-1}\right)$ em função da aplicação do resíduo da indústria processadora de goiabas

\begin{tabular}{|c|c|c|c|c|c|c|c|c|c|c|c|}
\hline \multirow{2}{*}{$\begin{array}{c}\text { Doses de resíduo } \\
\left(\mathrm{t} \mathrm{ha}^{-1}\right)\end{array}$} & \multicolumn{11}{|c|}{ Tempos de incubação (dias) } \\
\hline & 0 & 7 & 14 & 28 & 42 & 56 & 70 & 84 & 96 & 112 & 126 \\
\hline t ha-1 & \multicolumn{11}{|c|}{ mg $\mathrm{N} \mathrm{kg}^{-1}$} \\
\hline 9 & 0,00 & 6,71 & 8,11 & 0,22 & $-1,14$ & 0,45 & 2,80 & 2,76 & 10,25 & 2,76 & 15,77 \\
\hline 18 & 0,00 & 0,20 & 3,01 & $-0,76$ & 2,38 & 4,01 & 17,29 & 18,71 & 3,54 & 3,00 & 24,24 \\
\hline 36 & 0,00 & $-1,99$ & 5,36 & 1,93 & 4,87 & 7,91 & 8,45 & 19,18 & $-2,66$ & 3,89 & 31,94 \\
\hline
\end{tabular}

Tabela 3. Cálculos para a obtenção da fração de mineralização do nitrogênio, em função da aplicação do resíduo da indústria processadora de goiabas

\begin{tabular}{|c|c|c|c|c|c|c|}
\hline $\begin{array}{l}\text { Doses } \\
\left(\mathrm{t} \mathrm{ha}^{-1}\right)\end{array}$ & $\begin{array}{l}\mathrm{N} \text { total aplicado } \\
\left(\mathrm{mg} \mathrm{kg}^{-1}\right)\end{array}$ & $\begin{array}{l}\mathrm{N} \text { inorgânico } \\
\text { extraído } \\
\text { inicialmente } \\
\left(\mathrm{mg} \mathrm{kg}^{-1}\right)\end{array}$ & $\begin{array}{l}\text { N inorgânico } \\
\text { extraído após } \\
126 \text { dias } \\
\left(\mathrm{mg} \mathrm{kg}^{-1}\right)\end{array}$ & $\begin{array}{l}\mathrm{N} \text { mineralizado } \\
\text { após } 126 \text { dias } \\
\left(\mathrm{mg} \mathrm{kg}^{-1}\right)\end{array}$ & $\begin{array}{l}\text { N mineralizado } \\
\text { devido ao resíduo } \\
\left(\mathrm{mg} \mathrm{kg}^{-1}\right)\end{array}$ & $\begin{array}{c}\text { Fração de } \\
\text { mineralização do } \\
\mathrm{N} \text { em } 126 \text { dias } \\
(\%)\end{array}$ \\
\hline 0 & - & 1,08 & 3,34 & 2,27 & - & - \\
\hline 9 & 52,20 & 3,26 & 21,30 & 18,04 & 15,78 & 30,23 \\
\hline 18 & 104,40 & 5,04 & 31,55 & 26,50 & 24,24 & 23,21 \\
\hline 36 & 208,80 & 6,16 & 40,36 & 34,20 & 31,94 & 15,30 \\
\hline
\end{tabular}

Tabela 4. Nitrogênio aplicado, coeficiente de determinação $\left(\mathrm{R}^{2}\right)$ e parâmetros do modelo cinético de primeira ordem, meia-vida (T1²) e fração de mineralização (FM), obtidos após 126 dias de incubação do solo com o subproduto da indústria processadora de goiabas

\begin{tabular}{|c|c|c|c|c|c|c|}
\hline $\begin{array}{c}\text { Doses de resíduo } \\
\left(\mathrm{t} \mathrm{ha}^{-1}\right)\end{array}$ & $\begin{array}{l}\mathrm{N} \text { aplicado } \\
\left(\mathrm{mg} \mathrm{kg}^{-1}\right)\end{array}$ & $\mathbf{R}^{2}$ & $\begin{array}{c}\mathrm{N}_{0}^{*} \\
\left(\mathrm{mg} \mathrm{kg}^{-1}\right)\end{array}$ & $\begin{array}{c}k^{* *} \\
\left(\text { dia }^{-1}\right)\end{array}$ & $\begin{array}{c}\mathrm{T} 1 / 2 \\
\left(\mathrm{dia}^{-1}\right)\end{array}$ & $\begin{array}{l}\text { FM } \\
(\%)\end{array}$ \\
\hline 0 & 0 & 0,85 & 69,04 & 0,0242 & 28,64 & - \\
\hline 9 & 52,20 & 0,86 & 167,05 & 0,0119 & 58,24 & 30,23 \\
\hline 18 & 104,40 & 0,98 & 266,76 & 0,0090 & 77,00 & 23,21 \\
\hline 36 & 208,80 & 0,97 & 292,88 & 0,0083 & 83,51 & 15,30 \\
\hline
\end{tabular}

${ }^{*} \mathrm{~N}_{0}$ - nitrogênio potencialmente mineralizável; ${ }^{* *} \mathrm{k}$ - constante de mineralizaçăo. 
se grande elevação, mais de $400 \%$, com a aplicação do resíduo em sua maior dose, ou seja, houve ganhos na disponibilidade de nitrogênio. As constantes de mineralizaçáo $(\mathrm{k})$, ao contrário, diminuíram com o aumento das doses de subproduto aplicadas ao solo (Tabela 4), muito provavelmente devido à recalcitrância do material empregado, dificultando a ação dos microrganismos. Resultados semelhantes foram obtidos em ensaio de mineralização de nitrogênio com lodo de esgoto (BoEIra et al., 2002) e com água residuária da suinocultura (BARRos et al., 2010). O $\mathrm{T} 1 \frac{1}{2}$ (meia vida do nitrogênio do resíduo), tempo necessário para a degradação de $50 \%$ do $\mathrm{N}$ orgânico, aumentou com as doses aplicadas, e a meia vida variou entre 29 e 84 dias. $\mathrm{O}$ valor da meia vida correlaciona-se com a constante de mineralização, e com a aplicação de doses maiores do resíduo, há tendência de fornecimento de $\mathrm{N}$ mais lentamente. Pode-se afirmar que a mineralização do $\mathrm{N}$, ou sua liberação, é mais lenta, tendo comportamento semelhante ao do lodo de esgoto, o qual é o resíduo mais estudado e utilizado como referência. Boeira et al. (2002), trabalhando com o lodo de esgoto de Barueri, verificaram que houve mineralização lenta desse material orgânico.

Em amplo estudo sobre a mineralização potencial e líquida de nitrogênio orgânico em solos, correlacionando-o com a disponibilidade de $\mathrm{N}$ para as plantas, YAGI et al. (2009) concluíram que as quantidades de $\mathrm{N}$ potencialmente mineralizável, obtidas com incubação aeróbia, refletiram na mineralização e na disponibilidade de $\mathrm{N} \mathrm{em}$ longo prazo. Observaram, porém, que nem todo o $\mathrm{N}$ mineralizável se torna disponível às plantas devido à dinâmica do elemento, como lixiviação, imobilização microbiana $\mathrm{e}$, possivelmente, às perdas de $\mathrm{N}$ por desnitrificação.

Logo, a realizaçáo de experimentos no campo empregando resíduos pode elucidar melhor os resultados observados em condiçôes controladas, sendo pois recomendável sua condução.

$\mathrm{Na}$ figura 1 é apresentado o nitrogênio mineralizado acumulado $\left(\mathrm{NH}_{4}^{+}+\mathrm{NO}_{3}^{-}\right)$, ajustado à equaçáo de regressão exponencial de cinética de primeira ordem. No presente ensaio, a variação do $\mathrm{N}$ potencialmente mineralizável na camada de 0-20 cm de solo, representaria, em média: 138 (testemunha); 334 (dose de $9 \mathrm{t} \mathrm{ha}^{-1}$ ); 533 (dose de $18 \mathrm{t} \mathrm{ha}^{-1}$ ) e 586 (dose de $\left.36 \mathrm{t} \mathrm{ha}^{-1}\right) \mathrm{kg}$ de $\mathrm{N} \mathrm{ha}^{-1}$. De acordo com a sugestão de Natale et al. (1996), para produçôes superiores a $100 \mathrm{t}$ de frutos de goiabeira por hectare deve-se aplicar $400 \mathrm{~kg}$ de $\mathrm{N} \mathrm{ha}^{-1}$. Desta maneira, verifica-se que a utilização do resíduo da indústria processadora de goiabas supriria a demanda de $\mathrm{N}$ da cultura.
BARRETO et al. (2010) notaram como nitrogênio potencialmente mineralizável, em trabalho avaliando a serapilheira de solos cultivados com eucalipto, valores de 58 a $87 \mathrm{mg}$ $\mathrm{kg}^{-1}$, em ensaio de mineralização desenvolvido por 19 semanas de incubação, o que representa, segundo os autores, 70 a $104 \mathrm{~kg} \mathrm{ha}^{-1}$ na camada de $0-10 \mathrm{~cm}$.

Observa-se, ainda, que com a aplicação do resíduo, o potencial de mineralização de $\mathrm{N}$ aumentou 2,4 vezes com a dose de $9 \mathrm{t} \mathrm{ha}^{-1} ; 3,8$ vezes com a dose de $18 \mathrm{t} \mathrm{ha}^{-1} \mathrm{e}, 4,3$ vezes com a maior dose $\left(36 \mathrm{t} \mathrm{ha}^{-1}\right)$, em relaçáo à testemunha. BARRos et al. (2010) observaram que o valor de concentração de nitrogênio potencialmente mineralizável em solo com a aplicação de água residuária de suinocultura foi 2,5 vezes superior, em relação à concentração obtida sem a aplicação.

A taxa de aplicação do subproduto, calculada segundo a Cетеsв (1999) e Abreu et al. (2009), pode ser estimada em $72 \mathrm{t} \mathrm{ha}^{-1}$ de resíduo da indústria processadora de goiabas, considerando a aplicaçấo de $800 \mathrm{~g}$ de $\mathrm{N}$ por goiabeira, em pomar adulto $(7 \times 5 \mathrm{~m})$.

Boeira e Maximiliano (2009) citam que como a determinação da taxa agronômica de aplicação de resíduos é crítica na prevenção da lixiviação de nitrato, é importante o estudo da dinâmica de $\mathrm{N}$ em condiçôes tropicais, considerando o ajuste real das doses às necessidades das plantas cultivadas. Para isso, a maior dificuldade é a predição das taxas de mineralização de $\mathrm{N}$.

$\mathrm{Na}$ tabela 5 são apresentados os valores referentes ao comportamento do $\mathrm{pH}$, no período de estudo. Verifica-se que, para as doses de subproduto empregadas, há diminuição

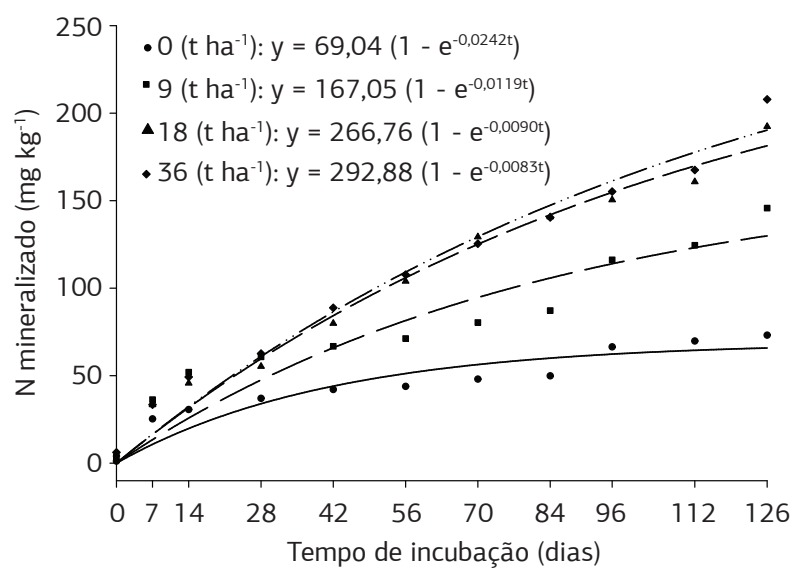

Figura 1. Efeitos da aplicação de doses do subproduto da indústria processadora de goiabas sobre o nitrogênio mineralizado, acumulado em 126 dias de incubação, sem lixiviação.

Tabela 5. Valores médios de $\mathrm{pH}\left(\mathrm{CaCl}_{2}\right)$ determinados no solo, em função da aplicação do resíduo da indústria processadora de goiabas

\begin{tabular}{|c|c|c|c|c|c|c|c|c|c|c|c|}
\hline \multirow{2}{*}{$\begin{array}{c}\text { Doses de resíduo } \\
\left(\mathrm{t} \mathrm{ha}^{-1}\right)\end{array}$} & \multicolumn{11}{|c|}{ Tempos de incubação (dias) } \\
\hline & 0 & 7 & 14 & 28 & 42 & 56 & 70 & 84 & 98 & 112 & 126 \\
\hline 0 & 6,7 & 6,6 & 6,6 & 6,5 & 6,3 & 6,6 & 6,4 & 6,3 & 6,3 & 6,2 & 6,6 \\
\hline 9 & 6,7 & 6,8 & 6,7 & 6,6 & 6,5 & 6,5 & 6,4 & 6,3 & 6,3 & 6,1 & 6,4 \\
\hline 18 & 6,5 & 6,6 & 6,5 & 6,8 & 6,4 & 6,4 & 6,3 & 6,3 & 6,6 & 6,1 & 6,3 \\
\hline 36 & 6,7 & 6,7 & 6,6 & 6,7 & 6,5 & 6,3 & 6,3 & 6,3 & 6,4 & 6,2 & 6,2 \\
\hline
\end{tabular}


do valor $\mathrm{pH}$ com o tempo de incubação. CorrêA et al. (2005) observaram resultados com o mesmo comportamento para o $\mathrm{pH}$ em solo incubado com o subproduto da indústria processadora de goiabas. Boeira et al. (2002) citam que há correlação significativa entre o valor $\mathrm{pH}$ e o nitrogênio determinado em estudos de incubação de resíduos.

Portanto, a aplicação do resíduo da indústria processadora de goiabas tende a acidificar o solo, principalmente com o uso de doses elevadas do subproduto.

\section{CONCLUSÃO}

A fração de mineralização do $\mathrm{N}$ orgânico, aplicado ao Argissolo via resíduo da indústria processadora de goiabas, é estimada em $23 \%$ e, a meia vida média é de 73 dias. A velocidade de mineralização é reduzida com o incremento das doses do resíduo.

Há potencial de uso do subproduto como fonte de nitrogênio para as plantas.

\section{REFERÊNCIAS}

ABREU, M.F.; ABREU JUNIOR; C.H.; SILVA, F.C.; SANTOS, G.C.G.; ANDRADE, J.C.; GOMES, T.F.; COSCIONE, A.R.; ANDRADE, C.A. Análise química de fertilizantes orgânicos (urbanos). In: SILVA, F.C. Manual de análises químicas de solos, plantas e fertilizantes. Brasília: Embrapa Informação Tecnológica, 2009. p.397-486.

BARRETO, P.A.B.; GAMA-RODRIGUES, E.F.; GAMARODRIGUES, A.C.; BARROS, N.F.; ALVES, B.J.R.; FONSECA, $S$. Mineralização de nitrogênio e carbono em solos sob plantaçôes de eucalipto, em uma sequência de idades. Revista Brasileira de Ciência do Solo, v.34, p.735-746, 2010.

BARROS, F.M.; MARTINEZ, M.A.; MATOS, A.T.; NEVES, J.C.L.; SILVA, D.D. Parametrização de modelos de mineralização de nitrogênio orgânico em solo tratado com água residuária da suinocultura. Revista Ambiente e Água, v.5, p.99-111, 2010.

BOEIRA, R.C. Uso do lodo de esgoto como fertilizante orgânico: disponibilização de nitrogênio em solo tropical. Jaguariúna: Embrapa Meio Ambiente, 2004. 3p. (Comunicado Técnico, 12)

BOEIRA, R.C.; LIGO, M.A.V.; DYNIA, J.F. Mineralização de nitrogênio em solo tropical tratados com lodo de esgoto. Pesquisa Agropecuária Brasileira, v.37, p.1639-1647, 2002.

BOEIRA, R.C.; LIGO, M.A.V.; MAXIMILIANO, V.C.B.; PIRES, A.M.M. Determinação da fração de mineralização de compostos nitrogenados de lodos de esgoto aplicados em solos agrícolas. Jaguariúna: Embrapa Meio Ambiente, 2009. 5p. (Comunicado Técnico, 20)

BOEIRA, R.C.; MAXIMILIANO, V.C.B. Mineralização de compostos nitrogenados de lodos de esgoto na quinta aplicação em Latossolo. Revista Brasileira de Ciência do Solo, v.33, p.711-722, 2009.
BRASIL. Ministério da Agricultura, Pecuária e Abastecimento. Instrução Normativa no 25 , de 23 de julho de 2009. Aprova as Normas sobre as especificaçōes e as garantias, as tolerâncias, o registro, a embalagem e a rotulagem dos fertilizantes orgânicos simples, mistos, compostos, organominerais e biofertilizantes destinados à agricultura. Diário Oficial [da] República Federativa do Brasil, Brasília, DF, 28 jul. 2009. Seção 1, p.20.

CANTARELLA, H.; TRIVELIN, P.C.O. Determinação de nitrogênio inorgânico em solo pelo método da destilação a vapor. In: RAIJ, B.van; ANDRADE, J.C.; CANTARELLA, H.; QUAGGIO, J.A. Análise química para avaliação da fertilidade de solos tropicais. Campinas: Instituto Agronômico, 2001. p.270-276.

CETESB. Aplicaçôes de lodos de sistema de tratamento biológico em áreas agrícolas. Critérios para projetos e operaçôes. São Paulo: Cetesb, 1999. 32p. (Norma P4.230)

COSCIONE, A.R.; ANDRADE, C.A. Protocolos para a avaliação dinâmica de resíduos orgânicos no solo. In: ANDRADE, J.C.; ABREU, M.F. Análise química de resíduos sólidos para monitoramento e estudos agroambientais. Campinas: Instituto Agronômico, 2006. p.159-177.

CORREAA, M.C.M.; FERNANDES, G.C.; PRADO, R.M.; NATALE, W. Propriedades químicas do solo tratado com resíduo orgânico da indústria processadora de goiabas. Revista Brasileira de Agrociência, v.11, p.241-243, 2005.

EMPRESA BRASILEIRA DE PESQUISA AGROPECUÁRIA. EMBRAPA. Sistema Brasileiro de classificação de solos. Rio de Janeiro, 1999. 412p. (Documentos, 15)

FRACARO, A.A; PEREIRA, F.M. Distribuição do sistema radicular da goiabeira 'Rica' produzida a partir de estaquia herbácea. Revista Brasileira de Fruticultura, v. 26, p.183-185, 2004.

MANTOVANI, J.R.; CORRÊA， M.C.M.; CRUZ, M.C.P.; FERREIRA, M.E.; NATALE, W. Uso de fertilizante de resíduo da indústria processadora de goiabas. Revista Brasileira de Fruticultura, v.26, p.339-342, 2004.

MANTOVANI, J.R.; FERREIRA, M.E.; CRUZ, M.C.P.; BARBOSA, J.C.; FREIRIA, A.C. Mineralizaçáo de carbono e de nitrogênio provenientes de composto de lixo urbano em Argissolo. Revista Brasileira de Ciência do Solo, v.30, p.677-684, 2006.

NATALE, W.; COUTINHO, E.L.M.; BOARETTO, A.E.; PEREIRA, F.M. Goiabeira: calagem e adubação. Jaboticabal: FUNEP, 1996. 22p.

NATALE, W.; PRADO, R.M.; ROZANE, D.E.; ROMUALDO, L.M. Efeitos da calagem na fertilidade do solo e na nutriçáo e produtividade da goiabeira. Revista Brasileira de Ciência do Solo, v.31, p.1475-1485, 2007.

RAIJ, B.van; ANDRADE, J.C.; CANTARELLA, H.; QUAGGIO, J.A. Análise química para avaliaçấo da fertilidade de solos tropicais. Campinas: Instituto Agronômico, 2001. 285p.

YAGI, R.; FERREIRA, M.E.; CRUZ, M.C.P.; BARBOSA, J.C. Mineralizaçáo potencial e líquida de nitrogênio em solos. Revista Brasileira de Ciência do Solo, v. 33, p.385-394, 2009. 